\title{
$\bullet$ IJCRR \\ Section: Healthcare \\ A Specific LC-ESI-MS/MS Method Development and Validation for the Quantification of Saquinavir in Biological Matrices
}

ISI Impact Factor (2020-21): 1.899

IC Value (2020): 91.47 $\operatorname{SJIF}(2020)=7.893$

(c) (i) (3)

Copyright@IJCRR

\author{
Bandaru Anil Kumar'1, Bomma Ramesh²
}

'Research Scholar, Career Point University, Kota, Rajasthan-325003, India; ${ }^{2}$ Research Supervisor, Career Point University, Kota, Rajasthan-325003, India.

\section{ABSTRACT}

Introduction: Saquinavir is a first protease inhibitor. Proteases are enzymes that cleave protein molecules into smaller fragments. No analytical procedure was reported for the estimation of saquinavir by LC-MS/MS.

Aims: The objective of the present research was to develop a specific liquid chromatography-electrospray ionization tandem mass spectrometric technique for the quantitation of saquinavir in biological matrices.

Methodology: Chromatographic elution was attained thru a Thermo Hypersil ODS stationary column having the dimensions of $50 \times 4.6 \mathrm{~mm}$ and particle size of $2.4 \mu \mathrm{m}$. Isocratic elution was processed with methanol and $0.1 \% \mathrm{~V} / \mathrm{V}$ formic acid in the ratio of 90:10 V/V as mobile phase with flow rate of $0.50 \mathrm{ml} / \mathrm{min}$. Liquid-liquid extraction was performed for drug and internal standard isolation with an ethyl acetate solvent. Parent and productions were monitored at $\mathrm{m} / \mathrm{z} 671.3 \rightarrow 654.3$ for saquinavir and 614.3 $\rightarrow 596.3$ for indinavir internal standardon multiple reaction monitoring.

Result: Linearity graph of drug was rectilinear in concentration over 260.4 . to $10416 \mathrm{ng} / \mathrm{ml}$ having r2(correlation coefficient) value more than 0.999 . Percentage of RSD findings were $\leq 5.3 \%$ for inter and intraday accuracy and precision. This procedure has good recoveries and \%recovery findings of lower quality control (LQC), median quality control (MQC) and higher quality control (HQC) samples were $94.6 \%, 92.4$ and $104.2 \%$ respectively.

Conclusion: Saquinavir has more stability for longer time when subjected for different stability environments and the technique was effectively relevant to routine analysis of saquinavir in biological matrix.

Key Words: Protease inhibitor, Saquinavir, LC-ESI-MS/MS, FDA guidelines, Specificity, Linearity

\section{INTRODUCTION}

Human immunodeficiency virus (HIV) infection and its clinical syndrome acquired immunodeficiency syndrome (AIDS) continue to be a major health problem worldwide. The development of highly effective antiretroviral chemotherapy for AIDS is found very useful in curbing the pandemic of this disease. ${ }^{1,2}$ The drug is sold as Fortovase and Invirase brand names and it acts as an antiretroviral agent utilized along with other medicines to prevent or treat HIV/AIDS. Normally it is combined with ritonavir/lopinavir or ritonavir to improve its outcome. Saquinavir is a first protease inhibitor. Proteases are enzymes that cleave protein molecules into smaller fragments. ${ }^{3}$

Bioavailability of saquinavir increases with ritonavir (PI) in dosage forms which was observed clinically. It will benefit to the patients for taking the less dose of saquinavir and also for maintaining adequate plasma levels of saquinavir to produce effective against the HIV. In this connection it was observed that ritonavir prevents isozyme cytochromeP450 3A4, which metabolize the saquinavir into its inactive metabolite. ${ }^{4}$

Drug bounds to effective part of viral protease and inhibits breakdown of viral polyprotein components, inhibiting maturation of virus. Saquinavir inhibits both HIV-1 and HIV-2 proteases. It is a potent inhibitor of HIV replication in vitro and suppresses viral load and increases CD4+ cell counts in HIV patients in vivo. Chemically saquinavir designated as (2S)- $N$-[(2S,3R)-4- [(3S)-3- (tert-butylcarbamoyl)-decahydroisoquinolin -2-yl] -3-hydroxy -1-phenylbutan -2-yl] -2(quinolin- 2- ylformamido) butanediamide with a molecular weight and formula of 670.841 and $\mathrm{C}_{38} \mathrm{H}_{50} \mathrm{~N}_{6} \mathrm{O}_{5}$ (Figure 1). ${ }^{5,6}$

\section{Corresponding Author:}

Bomma Ramesh, Research Supervisor, Career Point University, Kota, Rajasthan-325003, India.

Contact: +91-9866963059; Email: rameshbommapharm@gmail.com

ISSN: $2231-2196$ (Print)

Received: 05.10 .2021
ISSN: 0975-5241 (Online)

Revised: 12.11 .2021
Accepted: 14.12 .2021
Published: 15.02 .2022 
Literature on saquinavirrevealed that no analytical procedure for the estimation of drug in bulk and formulations was reported on LC-MS/MS. Few methods were reported on spectroscopy, ${ }^{7}$ liquid chromatography ${ }^{8-11}$ and ion pair chromatography. ${ }^{12}$ The development of specific method like LCMS/MS is highly essential for the quantification of saquinavirin biological matrices.

\section{MATERIALS AND METHODS}

\section{Chemicals and reagents}

Saquinavir (99.91\% purity) was acquired from Hetero drugs, Hyderabad, India. Methyl indinavir (Internal standard) of 99.89\% was received from MSN Labs, Hyderabad, India. Acetonitrile and methanol of HPLC-grade and formic acid of analytical grade were procured from J.T.Baker, Hyderabad, India. Water of Milli-Q was utilized during the processing of movable phase and washing solvents, acquired from in-built Milli-Q ${ }^{\circledR} \mathrm{RO}$ system.

\section{Liquid chromatographic-MS/MS system}

An LC-MS/MS SCIEX API4000 instrument furnished with a positive Electro-spray ionization (ESI) source and Shimadzu prominence HPLC comprising of SIL-HTC autosampler, binary pumps and column oven was utilized in the present work. Analyte quantitation, acquisition of data and it's integration were processed by utilizing analyst software-1.6.3 version.

\section{Liquid chromatography}

Chromatographic elution was attained on a Thermo Hypersil ODS stationary column having the dimensions of $50 \times 4.6$ $\mathrm{mm}$ and particle size of $2.4 \mu \mathrm{m}$. Column oven temperature was monitored at $30.0{ }^{\circ} \mathrm{C}$ and $0.5 \mathrm{~mL} / \mathrm{min}$ flow rate. Injection volume was $5 \mu \mathrm{L}$. Isocratic elution was processed with methanol and $0.1 \% \mathrm{~V} / \mathrm{V}$ formic acid in the ratio of $90: 10 \mathrm{~V} / \mathrm{V}$ as mobile phase. Saquinavir and indinavir internal standard were separated in the total runtime of 6 minutes. The autosampler temperature and analytical Column temperatures were kept at $5.0^{\circ} \mathrm{C}$ and $30.0^{\circ} \mathrm{C}$ respectively.

\section{Mass system conditions}

The mass spectrometer was operated under multiple reactions monitoring (MRM) mode in positive ion mode for both saquinavir and internal standard (IS). The adjusted mass system parameters for saquinavir and IS were: both of drying gas and sheath gas temperatures were $350{ }^{\circ} \mathrm{C}$. Nebulizer pressure was monitored at $25.0 \mathrm{psi}$. The sheath gas and drying gas flow rates were $10.0 \mathrm{~L} / \mathrm{min}$ and $5.0 \mathrm{~L} / \mathrm{min}$, respectively. Capillary voltage was set at $3.0 \mathrm{kV}$. Collision energy and fragment or voltage were $15 \mathrm{eV}$ and $120 \mathrm{~V}$ for saquinavir, $15 \mathrm{eV}$ and $100 \mathrm{~V}$ for IS. The transitions (precursor to product) monitored were $\mathrm{m} / \mathrm{z} 671.3 \rightarrow 654.3$ for saquinavir and $614.3 \rightarrow 596.3$ for IS. The dwell time was $200 \mathrm{~ms}$ for each transition.

\section{Calibration standards}

A stock solution of $1 \mathrm{mg} / \mathrm{mL}$ solution of saquinavir was prepared freshly by dissolving $10 \mathrm{mg}$ of drug in $10 \mathrm{~mL}$ of $70 \%$ methanol. Calibration standards of eight different concentration levels were processed by spiking blank plasma with saquinavir standard solution to get the concentrations of $260.4,520.8,1302,3100,5100,6950,8750$ and $10416 \mathrm{ng} /$ $\mathrm{mL}$.

\section{Quality Control Standards}

These solutions were prepared at three different levels of lowest quality control(LQC), standards, median quality control(MQC) standards and highest quality control(HQC) standards. These quality control(QC) samples were prepared according to calibration standards to get the concentration of 729.1, 5208 and $7812 \mathrm{ng} / \mathrm{mL}$ for LQC, MQC and HQC respectively. Prepared solutions were store at $-20^{\circ} \mathrm{c}$ till the time of analysis.

\section{Sample Preparation Method}

Sample solution was prepared by transferring $300 \mu 1$ of plasma and $50 \mu 1$ of indinavir $(1 \mu \mathrm{g} / \mathrm{mL})$ into a polypropylene tube and vortexed for $2 \mathrm{~min}$. Saquinavir and IS were extracted with $4 \mathrm{~mL}$ of ethyl acetate as solvent followed by centrifugation of the solution at $4500 \mathrm{rpm} / \mathrm{min}$ for $20 \mathrm{~min}$. After centrifugation, organic phase was separated and it was dried using lyophiliser. The resulting product was made solubilize in $250 \mu 1$ of mobile phase and then it transferred into a pre-labeled vials. The vials were kept in an auto-sampler and infused into LC-MS/MS system.

\section{Method validation}

The developed method was validated for the parameters: specificity, selectivity, linearity, stability, matrix effect, recovery, precision and accuracy. ${ }^{13,14}$

\section{RESULTS}

\section{Mass system conditions}

For the mass determination, we applied the MRM in positive mode with saquinavir to achieve higher sensitivity and better specificity. ESI was expected to be the best source of ions for LC-MS/MS and the precursor ions and product ions were ascertained by infusing the standard solutions into the mass instrument through a syringe pump. The product ions mass spectra of saquinavir and IS were obtained at $\mathrm{m} / \mathrm{z} 654.3$ an 596.3 which were selected as detection ions. Meanwhile, the parameters of mass spectrum environments (capillary voltage, 
ION-spray voltage and temperature, heater gas, nebulizer gas, collision gas and curtain gas and so on) were optimized to acquire higher mass response.

\section{Internal standard selection}

In the present study, indinavir was selected as the IS because it had similar chromatographic behaviors, ionization, extraction efficiency and retention action as the saquinavir and there was no obvious interferences found at the retention times of analytes and IS according to the method validation results.

\section{Method validation}

\section{Specificity}

Blank plasma samples obtained from six different batches of human plasma was spiked with the saquinavir at LLOQ and IS to assess the specificity. As Figure 2 showed, the retention times of saquinavir and IS were found to be 5.0 and 3.2 min, respectively. There was no noticeable intrusion of matrix substance and internal standard on saquinavir analytical data, and the response of all interfering peaks were less than $20 \%$ of LLOQ samples. ${ }^{14,15}$

\section{Sensitivity and linearity}

The method linearity was established for saquinavir and excellent linearity was exhibited in the concentration range of 260.4 to $10416 \mathrm{ng} / \mathrm{ml}$ (Table 1). The linearity graphs were produced by the peak area ratios $(y)$ of the saquinavir to the IS versus the concentrations ( $\mathrm{x}$ ) with the $1 / \mathrm{C}^{2}$ weighting factor. The developed method linearity equation of the calibration graphs was $\mathrm{y}=0.00843 \mathrm{x}+0.00249$ with a correlation coefficient $\left(r^{2}\right)$ value of 0.9991 . The LLOQ of saquinavir was $260.4 \mathrm{ng} / \mathrm{ml}$ (signal-to-noise ratio $>5.0$ ) assessed by 5 replicate sample solutions which were adequate for reliable quantitation of saquinavir in the plasma samples study. ${ }^{16}$

\section{Accuracy and precision}

The intra-batch and inter-batch precision and accuracy were evaluated by six spiked samples of plasma with saquinavir at LLOQ, LQC, MQC and HQC levels in a batch and in 3 succeeding batches, respectively. The results of precision and accuracy for quantitation of saquinavir were represented in the Table 2. The percentage relative standard deviation values of inter and intra-batch precision were present in the range of 2.8 to 5.3. The deviation of relative error in the accuracy of inter and intra-batch values were present in between -4.52 to $5.88 .{ }^{16,17-21}$

\section{Extraction recovery}

The biological samples were effectively pretreated before the analysis. The extraction recovery was evaluated by calculating the peak area ratio of LQC, MQC and HQC level solutions $(n=6)$ of saquinavir to the extracted spiked samples at respective concentration levels. In same manner, extraction recovery of indinavir was assessed by calculating the peak area ratio of quality control plasma sample solutions $(n=6)$ to spiked human plasma samples at respective concentration levels. The mean extraction recovery of saquinavir was 94.6\%, 92.4 and $104.2 \%$ at low, medium and high QC levels respectively. The mean extraction recovery of indinavir was $94.8 \%$ at the concentration of $100 \mathrm{ng} / \mathrm{L}$. The results were represented in the Table 3 and Figures 3 to $5 .^{15,18-21}$

\section{Matrix effect}

Co-eluting matrix constituents can reduce or increase ionization process in mass system, which may not produce a detectable response in blank matrix due to accuracy of the method. Hence, the different matrix related component ions dominance was assessed by estimating the IS normalized matrix factor in eight individual sources (consisting 2-hemolytic and 2-lipemic batches) of human plasma. The average IS normalized matrix factor for all the analytes were present in between 0.95 and 1.06 with a \%RSD of $\leq 4.99$ and the results were shown in the Table 4. ${ }^{16}$

\section{Dilution integrity}

The dilution integrity was processed at twice the concentration ULOQ (upper limit of quantification) for saquinavir. After the 1:4 dilution the average back-calculated drug content for dilution quality control samples were within $85-115 \%$ of the nominal value with a $\%$ RSD of $\leq 4.5$.

\section{Stability}

Stability of saquinavir was evaluated in both matrix and aqueous based samples. Saquinavir and indinavir in-stock solutions were not affected at $1-10^{\circ} \mathrm{C}$ for 70 days and stock solutions in diluent were not affected at $1-10^{\circ} \mathrm{C}$ for $48 \mathrm{~h}$. Matrix stability was assessed at -70 and $-20^{\circ} \mathrm{C}$ for 60 days. Matrix stability was analysed against freshly prepared spiked linearity standards. The findings of stability data were represented in Table 5. Drug was not degraded upto $20 \mathrm{~h}$ at the bench-top at a temperature of below $10^{\circ} \mathrm{C}$ and after six freeze-thaw cycles. The prepared sample solutions were stable at $10^{\circ} \mathrm{C}$ for $72 \mathrm{~h}$ in the auto-sampler. ${ }^{17}$

\section{DISCUSSION}

Method development was processed with different mobile phases and finally optimized with methanol and $0.1 \% \mathrm{~V} / \mathrm{V}$ formic acid in the ratio of $90: 10 \mathrm{~V} / \mathrm{V}$ thru Thermo Hypersil ODS $(50 \times 4.6 \mathrm{~mm}, 2.4 \mu \mathrm{m})$ column. Optimized method was validated as per the FDA and EMA guidelines for the specificity, selectivity, linearity, stability, matrix effect, recovery, precision and accuracy parameters. The LLOQQC was analysed with satisfactory accuracy, $<20 \%$ of precision and $>$ 5 of signal-to-noise $(\mathrm{S} / \mathrm{N})$ ratio. To evaluate the carry-over 
effect, the blank plasma solution was infused into chromatographic system after analyzing the highest concentration level of calibration standard in analytical run and there was no visible carry-over effect was found. The method has linearity in the concentration range of 260.4 to $10416 \mathrm{ng} / \mathrm{ml}$. These findings of precision and accuracy proved that they were reliable for the estimation of saquinavir in human plasma. Method has good extraction recovery with mean recovery of $97.07 \%$. Method was subjected for freeze-thaw, refrigerator, bench-top, long term and in-injector stability and has high degree of stability.

\section{CONCLUSION}

In the present research work, a sensitive and accurate LCMS/MS technique was developed and validated for the successful determination of saquinavir in human plasma. This method exhibited excellent specificity, linearity, accuracy, precision and stability. The linearity equation and correlation coefficient $\left(r^{2}\right)$ findings were $\mathrm{y}=0.00843 \mathrm{x}+0.00249$ and 0.9991 respectively. The \%RSD of intra and inter-day precision of the developed technique was found between 2.8 to 5.3\% for the QC-samples (260.4, 729.1, 5208 and $7812 \mathrm{ng} /$ $\mathrm{ml})$. Hence, the validated method can be applicable for the pharmacokinetic and toxicokinetic studies in the clinical and forensic analysis of saquinavir in different kinds of biological matrices successfully.

\section{ACKNOWLEDGEMENT}

Authors acknowledge immense help received from the scholars whose articles are cited and included in reference to the manuscript. The authors are grateful to all the authors/ editors/publisher of those articles, journals, and books from where the literature of this article has been reviewed and discussed. There is no source of funding for this study. There is no conflict of interest in this study.

Source(s) of funding: No funding is involved.

Conflicts of interest: The authors declare no conflicting interest.

Author's contribution: All the authors contributed equally.

\section{REFERENCES}

1. Invirase (saquinavir mesylate) Capsules and Tablets, for Oral Use. Full Prescribing Information (PDF). Genentech, Inc. Archived (PDF) from the original on 24 November 2015. Retrieved 23 November 2015.

2. Saquinavir. The American Society of Health-System Pharmacists. Archived from the original on 2015-09-08. Retrieved Sep $5,2015$.

3. Minor, Lisa K. Handbook of Assay Development in Drug Discovery. Hoboken: CRC Press; 2006. p. 117.
4. Hamilton, Richart. Tarascon Pocket Pharmacopoeia 2015 Deluxe Lab-Coat Edition. Jones \& Bartlett Learning; 2015. p. 72.

5. Winston A, Back D, Fletcher C. Effect of omeprazole on the pharmacokinetics of saquinavir-500 mg formulation with ritonavir in healthy male and female volunteers. AIDS. 2006;20(10):1401-6.

6. HIV Surveillance-United States, 1981-2008. Archived from the original on 9 November 2013. Retrieved 8 November 2013.

7. Sankar DG, Kumar JMR, Reddy MVVN. UV spectrophotometric methods for the determination of Saquinavir mesylate and efavirenz. A J of Chem. 2003; 15(3):1856-1858.

8. Riem Ha H, Follath F, Bloemhard Y, Krahenbuhl S. Determination of saquinavir in human plasma by high-performance liquid chromatography. J of Chrom.B. 1997;694:427-433.

9. Ucpinar SD, Stavchansky S. Quantitative determination of saquinavir from Caco-2 cell monolayers by HPLC-UV. High performance liquid chromatography. Biomed Chromatogr. 2003; 17(1):21-25.

10. Takahashi M, Yoshida M, Oki T, Okumura N, Suzuki T, Kaneda T. Conventional HPLC Method Used for Simultaneous Determination of the Seven HIV Protease Inhibitors and Non-nucleoside Reverse Transcription Inhibitor Efavirenz in Human Plasma. Biol. Pharm. Bull. 2005;28(7):1286-1290.

11. Prakash VK, Venkateswara Rao J, Appala Raju N. Estimation of Saquinavir Mesylate in Tablet Dosage Form using RP-HPLC. A J of Chem. 2009;21:612-616.

12. Richard Hoetelmans MW, Marjolijn Van E, Pieter Meenhorst L, Jan Mulder W, Jos Beijnen H. Determination of saquinavir in human plasma, saliva, and cerebrospinal fluid by ion-pair highperformance liquid chromatography with ultraviolet detection. J Chrom. B. 1997; 698:235-241.

13. FDA Guidance for Industry, Bioanalytical Method Validation, US Department of Health and Human Services, Food and Drug Administration, Centre for Drug Evaluation and Research (CDER), Center for Veterinary Medicine (CVM) May 2001.

14. European Medicines Agency, Guideline on bioanalytical method validation 2011.

15. Henion J, Brewer E, Rule G. Sample Preparation for LC/MS/ MS: Knowing the Basic Requirements and the Big Picture of an LC/MS System can Ensure Success in Most Instances. Anal Chem. 1998;70:650A-656A.

16. Chambers EE, Woodcock MJ, Wheaton JP. Systematic development of an UPLC-MS/MS method for the determination of tricyclic antidepressants in human urine. J. Pharm. Biomed. Anal. 2014;88:660-665.

17. Patel DS, Sharma N, Patel MC. Development and validation of a selective and sensitive LC-MS/MS method for determination of cycloserine in human plasma: application to bioequivalence study, J Chromatogr B. 2011; 879:2265-2273.

18. Hindu K, Vinodhini C, Srinivas SK, Rajan SM, Chitra K, Mangathayaru K. Validated RP-HPLC Method for Quantification of Paclitaxel in Human Plasma - Eliminates Negative Influence of Cremophor EI. IJCRR. 2018;10(13):5-10.

19. Murphy AT, Kasper SC, Gillespie TA, DeLong AF. Determination of Xanomeline and Active Metabolite, N-Desmethylxanomeline, in Human Plasma by Liquid Chromatography-Atmospheric Pressure Chemical Ionization Mass Spectrometry. J. Chromatogr B. Biomed Appl. 1995;668:273-280.

20. Nagalakshmi V, Srinivas Rao G, Gayathri Devi N, Mohan S. RP-HPLC Method for Simultaneous Estimation of Vildagliptin and Metformin in Bulk and Pharmaceutical Formulations. IJCRR. 2021. 13(7)112-117.

21. Cheruku S, Bhikshapathi DVRN. Validation of a specific LCMS/MS method for the quantification of anti-cancer alectinib in biological matrices. IJPR. 2021;13(1):6513-21. 


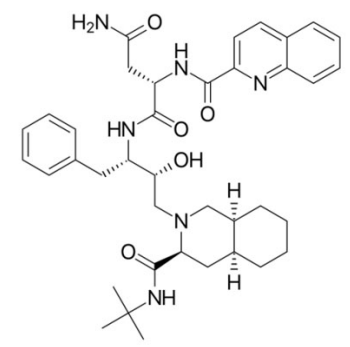

Figure 1: Structure of Saquinavir.

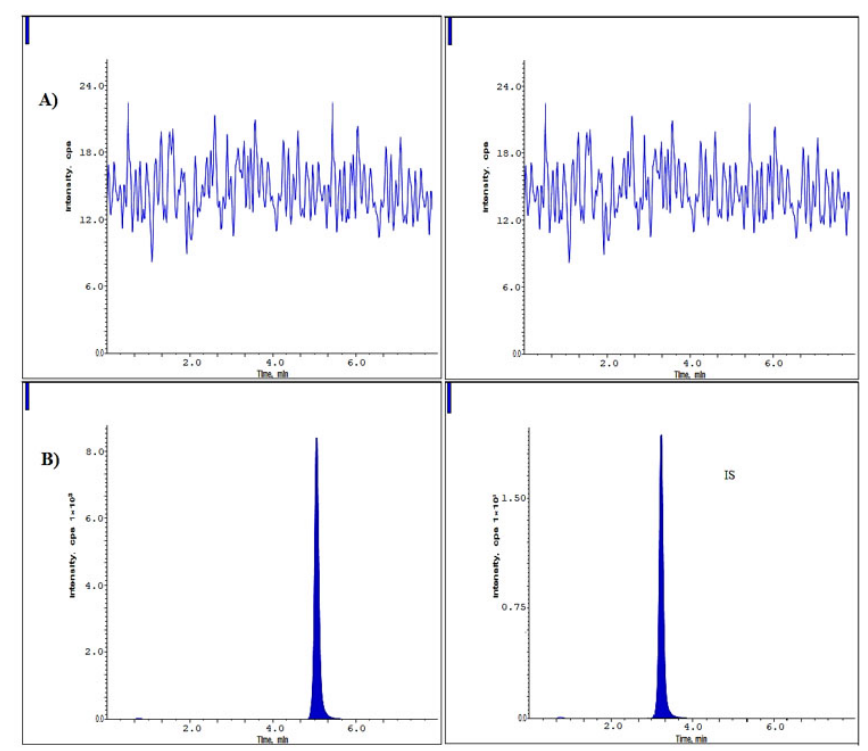

Figure 2: Chromatograms of blank plasma (A) and LLOQ (B) samples.

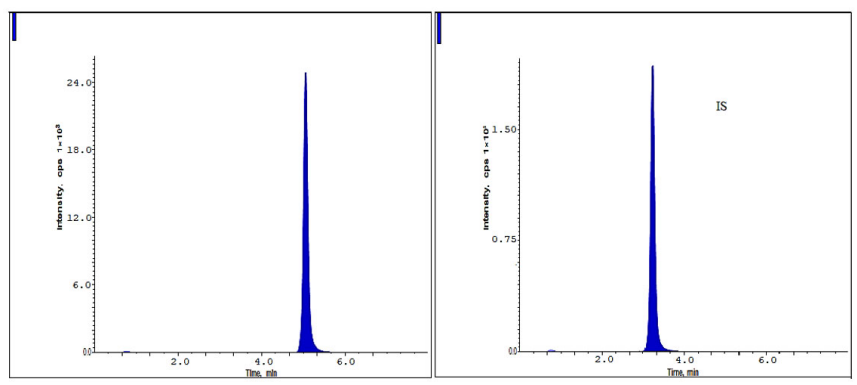

Figure 3: Chromatograms of saquinavir at LQC level.

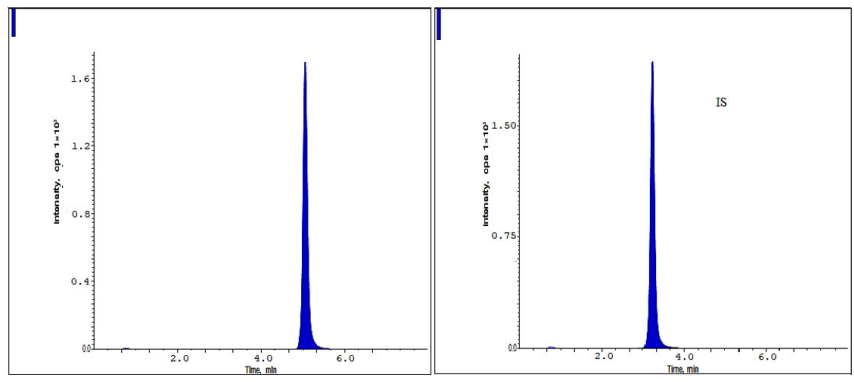

Figure 4: Chromatograms of saquinavir at MQC level.

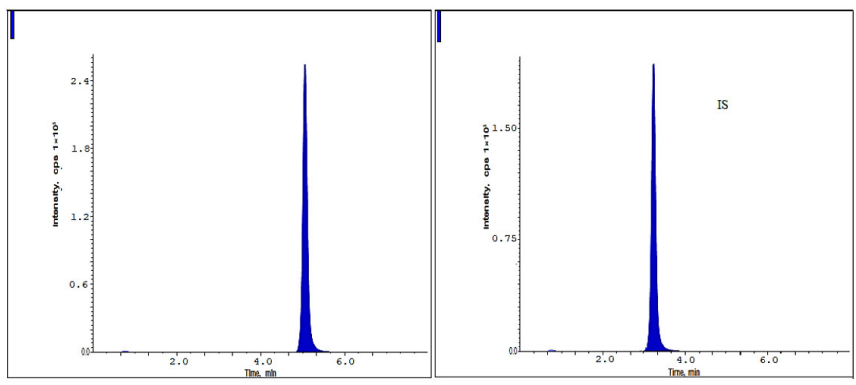

Figure 5: Chromatograms of saquinavir at HQC level.

Table 1: Calibration standards for saquinavir.

\begin{tabular}{lcccc} 
CS-ID & $\begin{array}{c}\text { Concentration } \\
(\mathrm{ng} / \mathrm{ml})\end{array}$ & $\begin{array}{c}\text { Mean }^{\mathrm{a}} \\
(\mathrm{ng} / \mathrm{ml})\end{array}$ & \%RSD & \%RE \\
CS-1 & 260.4 & 255.4 & 3.8 & 1.92 \\
CS-2 & 520.8 & 512.6 & 2.7 & 1.57 \\
CS-3 & 1302 & 1351 & 2.1 & -3.76 \\
CS-4 & 3100 & 2995 & 4.2 & 3.39 \\
CS-5 & 5100 & 5236 & 3.5 & -2.67 \\
CS-6 & 6950 & 7024 & 1.9 & -1.06 \\
CS-7 & 8750 & 8513 & 2.9 & 2.71 \\
CS-8 & 10416 & 9976 & 3.7 & 4.22 \\
\hline
\end{tabular}

CS- Calibration standard; RSD- Relative standard deviation; RE- Relative error

Table 2: Intra-batch and Inter-batch Accuracy and Precision

\begin{tabular}{lccccccc}
$\begin{array}{l}\text { Concentration } \\
\text { level }\end{array}$ & $\begin{array}{c}\text { Nominal concen- } \\
\text { tration } \\
(\mathbf{n g} / \mathbf{m l})\end{array}$ & $\begin{array}{c}\text { Intra-batch } \\
\text { Amount found } \\
(\mathbf{n g} / \mathbf{m l})\end{array}$ & \%RSD & \%RE & $\begin{array}{c}\text { Inter-batch } \\
\text { Amount found } \\
(\mathbf{n g} / \mathbf{m l})\end{array}$ & \%RSD & \%RE \\
LLOQ & 260.4 & 248.8523 & 4.1 & -4.52 & 254.63 & 2.8 & -2.21 \\
LQC & 729.1 & 755.4857 & 3.1 & 3.62 & 773.96 & 5.2 & 6.15 \\
MQC & 5208 & 5352.346 & 2.9 & 2.77 & 5415.85 & 3.7 & 3.99 \\
HQC & 7812 & 7857.036 & 5.3 & 0.58 & 8271.02 & 2.4 & 5.88 \\
\hline
\end{tabular}

RSD: Relative standard deviation; RE: Relative error; 
Table 3: Extraction Recovery of saquinavir and IS.

\begin{tabular}{lccccc} 
Concentration level & A & B & \% Recovery & \% Mean recovery & \%RSD \\
LQC & 24430 & 23110 & 94.6 & & 57.07 \\
MQC & 174500 & 161238 & 92.4 & & 5.28 \\
HQC & 261750 & 272743 & 104.2 & & \\
IS & 191216 & 181272 & 94.8 & \\
\hline
\end{tabular}

RSD- Relative standard deviation; A, mean recoveries of un-extracted samples; B, average recovery of extracted samples.

Table 4: Matrix Effect Results.

\begin{tabular}{|c|c|c|c|c|c|c|}
\hline \multirow[t]{2}{*}{ Saquinavir } & \multicolumn{3}{|c|}{ LQC level } & \multicolumn{3}{|c|}{ HQC level } \\
\hline & Analyte MF & IS MF & IS normalized MF & Analyte MF & IS MF & IS normalized MF \\
\hline L-1 & 1.09 & 1.13 & 0.96 & 1.12 & 1.08 & 1.04 \\
\hline$L-2$ & 1.05 & 1.09 & 0.96 & 1.09 & 1.1 & 0.99 \\
\hline$L-3$ & 1.11 & 1.03 & 1.077 & 1.07 & 1.02 & 1.05 \\
\hline $\mathrm{L}-4$ & 1.12 & 1.11 & 1.00 & 1.03 & 1.1 & 0.95 \\
\hline$L-5^{\mathrm{a}}$ & 1.11 & 1.08 & 1.02 & 1.08 & 1.11 & 0.97 \\
\hline$L-6^{a}$ & 1.13 & 1.07 & 1.05 & 1.12 & 1.02 & 1.09 \\
\hline$L-7^{b}$ & 1.08 & 1.12 & 0.96 & 1.09 & 1.11 & 0.98 \\
\hline$L-8^{b}$ & 1.02 & 1.09 & 0.93 & 1.16 & 1.09 & 1.06 \\
\hline Mean & \multicolumn{3}{|c|}{0.99} & \multicolumn{3}{|c|}{1.016} \\
\hline SD & \multicolumn{3}{|c|}{0.047} & \multicolumn{3}{|c|}{0.05} \\
\hline$\%$ RSD & \multicolumn{3}{|c|}{4.745} & \multicolumn{3}{|c|}{4.98} \\
\hline
\end{tabular}

a, Hemolyzed lot; b, Lipemic lot; MF, matrix factor; RSD, Relative standard deviation

Table 5: Stability Results of Saquinavir

\begin{tabular}{llcccc} 
Parameter & QC level & X & Y & \%RSD & \%Stability \\
Freeze and thaw stability & LQC & 260.4 & 248.5121 & 4.2 & 95.43475 \\
& HQC & 7812 & 7976.19 & 2.9 & 102.1018 \\
Stability in refrigerator $\left(1-10^{\circ} \mathrm{C}\right.$ for $\left.48 \mathrm{~h}\right)$ & LQC & 260.4 & 268.4834 & 3.4 & 103.1042 \\
& HQC & 7812 & 8101.558 & 1.9 & 103.7066 \\
Bench-top stability $\left(\right.$ at $<10^{\circ} \mathrm{C}$ for $20 \mathrm{O}$ ) & LQC & 260.4 & 272.5972 & 2.5 & 104.684 \\
& HQC & 7812 & 7458.641 & 3.7 & 95.47672 \\
Long term stability $\left(60\right.$ days at $\left.-20^{\circ} \mathrm{C}\right)$ & LQC & 260.4 & 277.7627 & 5.8 & 106.6677 \\
& HQC & 7812 & 7627.526 & 2.7 & 97.63858 \\
In-injector stability $\left(\right.$ at $10^{\circ} \mathrm{C}$ for $\left.72 \mathrm{~h}\right)$ & LQC & 260.4 & 267.7616 & 6.2 & 102.8271 \\
& HQC & 7812 & 8118.302 & 1.61 & 103.9209 \\
Long-term stability $\left(60\right.$ days at $\left.-70^{\circ} \mathrm{C}\right)$ & LQC & 260.4 & 248.7905 & 2.4 & 95.54165 \\
& HQC & 7812 & 7801.318 & 4.6 & 99.86327 \\
\hline
\end{tabular}

$\mathrm{X}$, nominal concentration $(\mathrm{ng} / \mathrm{ml}) ; \mathrm{Y}$, mean concentrations $(\mathrm{ng} / \mathrm{ml})$ of analytes 